\title{
UNMANNED CONSTRUCTION SYSTEM: PRESENT STATUS AND CHALLENGES
}

\author{
Yoshio Ban ${ }^{1}$
}

\begin{abstract}
This report analyzes past unmanned construction system done at the Unzen-fugendake and Usuzan volcanoes to organize the present status of unmanned construction systtem from varied perspectives, describes challenges and countermeasures, and introduces future prospects.

Unmanned construction systtem have been done to perform emergency countermeasure work and restoration work at disaster sites. Remaining challenges include development of methods of performing remote hillside reforestation in devastated areas, remote traveling crane operation. Turning to the future, it is proposed that noise and vibration be provided around the operator's seat in remote control rooms to create a sense of realism. Unmanned construction systtem should be used not only at disaster restoration sites, but also used effectively to increase safety at ordinary construction sites.
\end{abstract}

KEYWORDS: Unmanned construction, remote operation, hillside reforestation, traveling crane, rough terrain crane

\section{INTRODUCTION}

Unmanned construction is work performed by remotely operated construction machinery that corresponds to an operator controlled robot. Unmanned construction was used in civil engineering work for the first time in Japan in 1969 when an underwater bulldozer was used to excavate and move deposited soil during emergency restoration work at the Toyama Bridge that had been blocked by the Joganji River disaster. Since then, unmanned construction by excavators inside pneumatic caissons and by backhoes have been carried out, but the restoration work following the volcanic eruptions that began in 1994 at the Unzen-fugendake Volcano and restoration work executed following the eruption of the Usuzan Volcano in 2000 were the first executions of large-scale unmanned construction and have spurred rapid progress in unmanned construction technologies and encouraged their wide use.

This report analyzes recent applications of the unmanned construction method including those at Unzen-fugendake and Usuzan
Volcanoes, outlines the present state of unmanned construction from multiple perspectives, discusses future challenges and measures to overcome them, and concludes with future prospects for the method.

\section{ANALYSIS OF THE PRESENT STATE OF UNMANNED CONSTRUCTION}

The following are analyses of unmanned construction executed at the Unzen-fugendake and Usuzan Volcanoes.

\subsection{Work Categories}

Past executions can be broadly categorized as emergency works executed at the time of a disaster and later restoration works. The method has often been used after disasters including those caused by debris flows and pyroclastic flows, the collapse of soil caused by earthquakes and so on.

The following are the principal categories of work performed by this method.

\footnotetext{
${ }^{1}$ Advanced Construction Tecknology Center, 2-15-6 Otsuka Bunkyo-ku, Tokyo, Japan (T) 03-3942-3992

(F) 03-3942-0424 E-mail ban@actec.or.jp
} 
Table 1. Principal Categories of Work Performed by this Method

\begin{tabular}{|l|l|}
\hline \multicolumn{1}{|c|}{ Work Category } & \multicolumn{1}{|c|}{ Description of the works } \\
\hline Rock removal work & $\begin{array}{l}\text { Excavation, loading, } \\
\text { transporting }\end{array}$ \\
\hline $\begin{array}{l}\text { Structure demolition and } \\
\text { removal work }\end{array}$ & $\begin{array}{l}\text { Crushing and pulverizing } \\
\text { concrete and cutting steel } \\
\text { reinforcing bars, loading and } \\
\text { transporting the products }\end{array}$ \\
\hline $\begin{array}{l}\text { Large sandbag placing } \\
\text { work }\end{array}$ & Transporting and placing \\
\hline Concrete block work & $\begin{array}{l}\text { Removing obstructions, } \\
\text { leveling ground, placing }\end{array}$ \\
\hline Temporary road work & $\begin{array}{l}\text { Cutting, filling, and } \\
\text { compaction }\end{array}$ \\
\hline $\begin{array}{l}\text { Erosion and sediment } \\
\text { control dam work }\end{array}$ & $\begin{array}{l}\text { Excavation, embanking, } \\
\text { backfilling, compaction, } \\
\text { pouring concrete }\end{array}$ \\
\hline Watercourse work & $\begin{array}{l}\text { Excavation, pouring concrete, } \\
\text { placing foot protection blocks }\end{array}$ \\
\hline Tree felling work & Cutting, stumping, transporting \\
\hline RCC work & $\begin{array}{l}\text { Transporting, spreading and } \\
\text { leveling, compaction, spraying, } \\
\text { laitance removal }\end{array}$ \\
\hline $\begin{array}{l}\text { Ready-mix concrete } \\
\text { work }\end{array}$ & $\begin{array}{l}\text { Installing form materials, } \\
\text { pouring and compacting } \\
\text { concrete }\end{array}$ \\
\hline $\begin{array}{l}\text { Excavation, loading, } \\
\text { transporting, removing form } \\
\text { materials }\end{array}$ \\
\hline
\end{tabular}

\subsection{Remotely Operated Construction Machinery}

The following are types of remotely controlled construction machinery that have been used frequently.

Table 2. Frequently Used Remotely Controlled Construction Machinery

\begin{tabular}{|l|l|}
\hline \multicolumn{1}{|c|}{ Machine Type } & \multicolumn{1}{c|}{ Standards } \\
\hline Back hoes & 0.6 to $4.3 \mathrm{~m}^{3}$ \\
\hline Bulldozers & 16 to $80 \mathrm{t}$ \\
\hline Dump trucks & 32 to $80 \mathrm{t}$ \\
\hline $\begin{array}{l}\text { Crawler type trucks (large tracked } \\
\text { trucks) }\end{array}$ & 6 to $12 \mathrm{t}$ \\
\hline
\end{tabular}

In addition, towed transport vehicles, trucks, tractor shovels, crawler cranes, self-propelled cranes, crane trucks, vibrating rollers, etc. have been used.

\subsection{Unmanned Construction Equipment}

The following are the types of unmanned construction equipment that have been used according to the radio transmission distance.

Table 3. State of Use of Unmanned Construction Equipment

\begin{tabular}{|c|c|c|c|c|}
\hline $\begin{array}{c}\text { Radio } \\
\text { transmissio } \\
\mathrm{n} \text { distance }\end{array}$ & $\begin{array}{l}\text { Remote } \\
\text { operation } \\
\text { room }\end{array}$ & $\begin{array}{l}\text { Radio } \\
\text { relay } \\
\text { truck }\end{array}$ & $\begin{array}{l}\text { Mobile } \\
\text { camera } \\
\text { vehicle }\end{array}$ & $\begin{array}{l}\text { Stationary } \\
\text { camera }\end{array}$ \\
\hline $\begin{array}{l}\text { Shorter than } \\
50 \mathrm{~m}\end{array}$ & O & - & \multirow{3}{*}{\multicolumn{2}{|c|}{$\begin{array}{l}\text { Used according to } \\
\text { circumstances }\end{array}$}} \\
\hline $\begin{array}{l}50 \mathrm{~m} \text { to } 150 \\
\mathrm{~m}\end{array}$ & 0 & - & & \\
\hline $\begin{array}{l}\text { Longer than } \\
150 \mathrm{~m}\end{array}$ & O & - & & \\
\hline
\end{tabular}

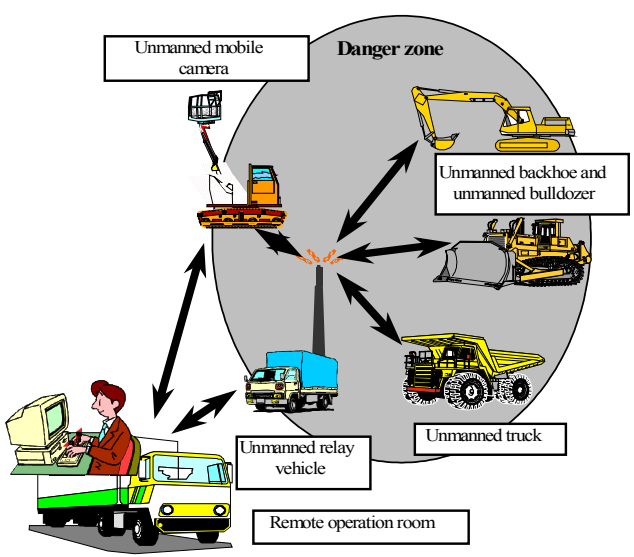

Figure 1. Configuration of Unmanned Construction Equipment

\subsection{Types of Radio Equipment}

The frequencies of radios used for unmanned construction are $400 \mathrm{MHz}, 2.4 \mathrm{GHz}, 50 \mathrm{GHz}$ etc. Various innovations include lowering their transmission power to limit their range, thereby avoiding the need for licensing. Each radio base station is selected according to the transmission distance, rectilinearity, channel capacity, data transmission capacity, licensing requirement, and other differences, and according to the work environment.

\subsection{Transporting, Assembling, and Modifying the Machinery}

The number of days required to obtain the machinery is a problem that must be resolved, particularly when performing emergency 
restoration at the time of a disaster. The number of days required to acquire the machinery varies sharply between cases where machinery already equipped with remote control systems is transported to the site and cases where the hydraulic circuits of construction machinery are modified. In the past, it has taken a few days in the former cases and a few months in the latter cases.

\subsection{Work Efficiency}

It is said to be roughly $60 \%$ to $70 \%$ of that of manned construction, but the efficiency falls sharply in cases where the machinery moves, where materials are transported in dump trucks for example, and in cases where high precision work is necessary.

\subsection{Controlling and Inspecting the Construction}

Work requiring extensive finished work control is now done by manned methods. The following systems are used for unmanned construction.

1) Automatic tracking type total station

A prism that functions as a target and a marking spray device are installed on the front of a remotely controlled back hoe, and the automatic tracking total station measures the target to mark the position to install the back hoe and to confirm its position is correct.

2) GPS precise real time positioning system This technology accurately computes the position of each working machine by combining information about the position of the machines obtained by RTK-GPS with status information provided by sensors installed on various parts of the construction machinery. For example, in some cases, GPS receivers and prisms have been installed on bulldozers or vibrating rollers etc. so the system can perform coordinate control by obtaining measured data to control the spread thickness or the compaction frequency.

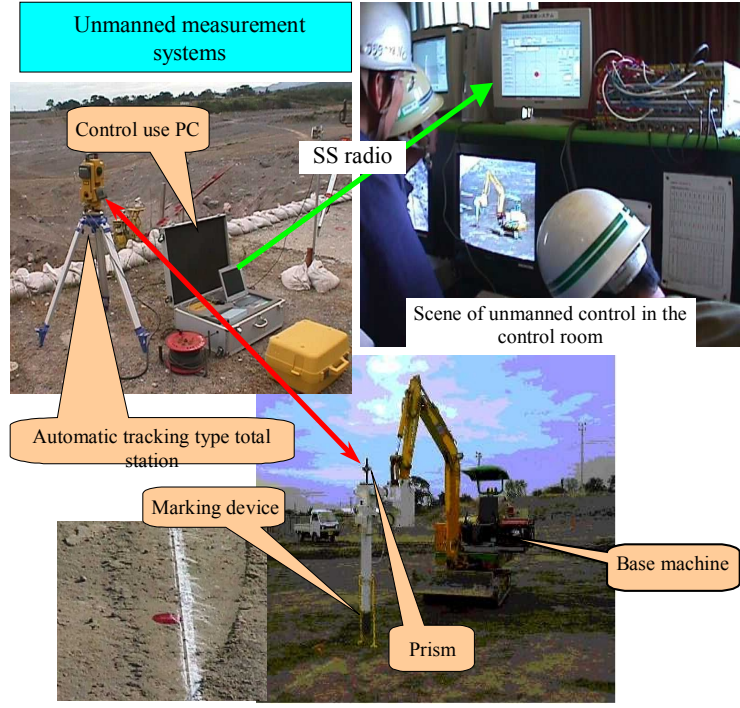

Photograph 1. Unmanned Measurement Systems

\section{FUTURE CHALLENGES FACING UNMANNED CONSTRUCTION AND MEASURES TO OVERCOME THEM}

\subsection{Work Categories (introduction of unmanned hillside reforestation)}

It is expected that in addition to various work categories in sediment and erosion control work such as permeable dam construction or precast block masonry work, unmanned executions will play an important role in hillside work in devastated areas carried out to prevent disasters and to conserve the environment.

Hillside work is broadly categorized as hillside foundation work and hillside reforestation work. Hillside foundation work is done to lay the foundation for a future forest by stabilizing deposited sediment, while hillside reforestation refers to introducing trees directly on hillsides to form forests that will prevent the runoff of sediment. Execution methods that can be used for the former, hillside foundation work, are concrete block masonry work, placing large sandbags, and placing boulders at the site: methods that can be executed with existing technologies. The latter, hillside reforestation, has been done as unmanned reforestation spreading work: spreading seeds and other materials with a high speed belt conveyor type spreading machine. And although it has not been done unmanned, seeds have been sown from the air by manned helicopters for several decades. 


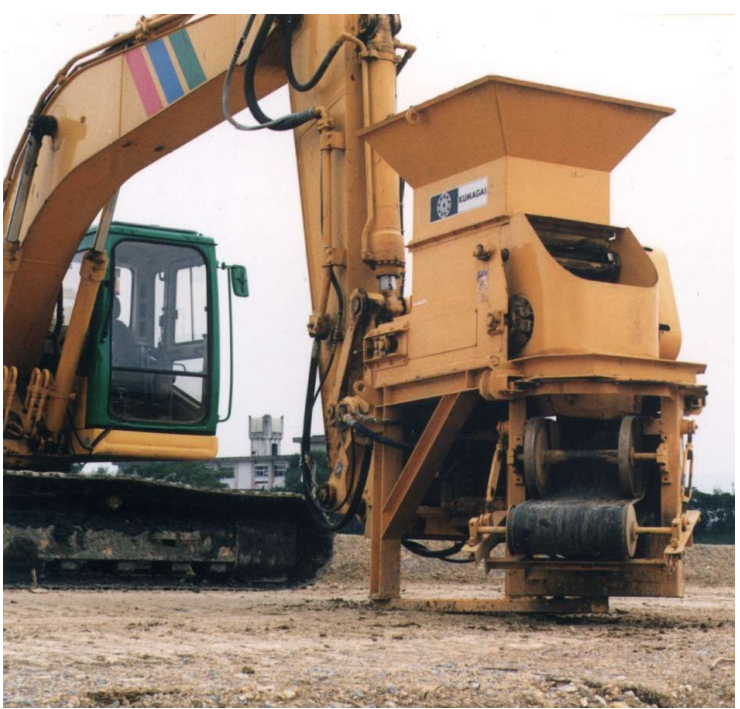

Photograph 2. High Speed Belt Conveyor Type Spreading Machine

But on devastated ground where the soil condition is poor and the sediment moves, reforestation by transplanting seedlings is more reliable than seeding work, so there is a demand for unmanned transplanting methods.

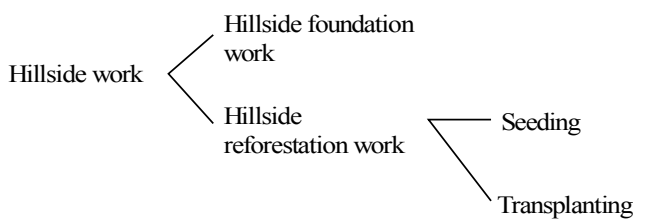

The wood frame block root pot method has been proposed as an unmanned transplanting work method. Seedlings are grown inside wood framed blocks consisting of a wooden frame, (approx. $1.0 \mathrm{~m} \cdot 1.0 \mathrm{~m}$ ), net (palm fiber etc.), water holding material, and leaf mold, and the frames are placed in rows by an unmanned backhoe equipped with a holding device. This method does not require separate works such as digging holes and mulching, and it can be used on any slope where a backhoe can be operated. It should be introduced as a working system in the future.

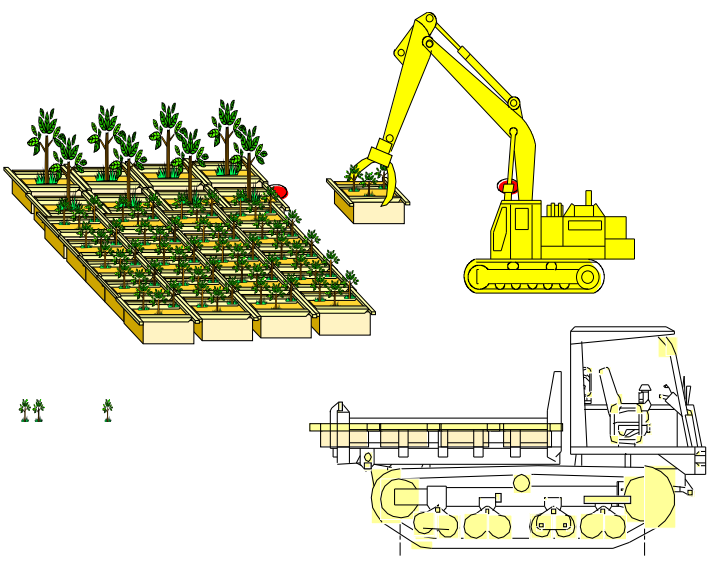

Figure 2. Image of Unmanned Transplanting

\subsection{Remotely Operated Construction Machinery (introduction of unmanned traveling cranes)}

In June 2002, the Ministry of Land, Infrastructure and Transport of Japan announced that it had begun to develop unmanned operating technology for traveling cranes. Till now, medium and large traveling cranes have never been remotely operated and developing the world's first successful unmanned operating system for large cranes will be a great achievement. Because cranes may be installed in narrow places and on slopes, the crane chosen for the development project was a rough terrain crane, a type that can be kept in a horizontal attitude with an outrigger and handled in narrow spaces. (lifting capacity: 50 tons)

A rough terrain crane, which is a type of wheeled crane that is propelled by a single engine and can perform crane work, travels easily over uneven ground because it is a four wheel drive vehicle and all four wheels can be steered. Traveling and crane work are controlled from the same operating cab. Although externally it appears more compact than a track crane, it provides comparable lifting capacity. In Japan, therefore, most cranes manufactured are traveling cranes.

The first step in the development is to decide which traveling crane functions will be performed remotely. Because cranes work while installed in dangerous locations, almost all traveling and crane operation functions must be remotely operated. Because unmanned construction is performed rarely, it must also be possible for the crane to be operated by an 
operator sitting in the cab when it is used in safe places.

The next problems is attaching and detaching loads. It is extremely difficult to attach loads to and detach them from the hook by the remote control method. An automatic load detachment device operated by a weak radio wave has already been developed and is in use on small cranes. The following two solutions are being considered. One is to replace hooks with a newly developed device that attaches a load by grasping it. The second is to limit attachment work to manned areas. (If attachment work is limited to manned areas, the working range of a $50 \mathrm{t}$ class rough terrain crane will be about $60 \mathrm{~m}$ from the boundary of the manned and unmanned areas.)

The next problem is the "prohibition on leaving the operating location." Japanese law includes a provision that states, "The operator of a traveling crane shall not leave the operating location while a load is still suspended by the crane" (Regulation for Safe Operation of Cranes Etc.). Therefore, to comply with the Regulation for Safe Operation of Cranes Etc., an operator's seat must be provided in the remote control room and it must be equipped with a device that can provide the same information available at the operator's seat in the crane. Specifically, it is necessary to provide a system that converts the boom angle, rotation angle, and other quantities representing the state of the crane, overload warnings, and visual information about the load and the wire (visual data) into electronic data and transmits this data to the operating room.

When unmanned crane work has been realized, it is counted on to be applied to various kinds of work in dangerous locations. Expanding the working radius of unmanned construction will not only permit execution of construction work in previously inaccessible locations; it is also counted on to permit the installation of larger blocks, increasing work efficiency.

\section{FUTURE PROSPEC}

\subsection{An operator's Seat with a Sense Reality}

When unmanned execution is too far away for the operator to see the site, the operator remotely controls the execution in a remote control room while watching images transmitted from television cameras. Even when relatively simple work such as backhoe or bulldozer work is executed, the operator uses two or more television cameras that provide views of the overall scene and the view from the cab of the machine. To perform work requiring detail operations or depth perception, special measures are taken at each site, installing another camera providing a view from the side.

But during manned work (when the operator sits in the seat in the cab of the construction machine), the operator operates the machine while unconsciously obtaining information other than visual information (noise, vibration, deviation from the horizontal, etc.), and this difference is the cause of gaps in execution efficiency, execution precision, and reliability between manned and unmanned work.

In the future, the operator's seat must be made more realistic by adding noise, vibration, and other information useful for operators so that they can make the maximum use of their five senses.

\subsection{Changeover to Safer Construction Methods}

Unmanned executions can be divided into the following three stages.

(1) Emergency measures work at a disaster location

(2) Restoration work at a disaster location

(3) Ordinary work at dangerous locations

Now that unmanned construction has been firmly established and has gained a good reputation as disaster site restoration work method, it is expected to advance to the next step: as a method of achieving safer work at normal construction sites.

The following are considered to be dangerous places to execute civil engineering works. 
- Slopes at risk of failure (sediment control dam work, hillside work, slope work)

- High places (slope work, concrete dam work)

- Riverbeds and lake bottoms (dredging work)

- Seabed (dredging work, leveling riprap)

- High pressure environments (pneumatic caissons)

- Places at risk of a gas explosion (vertical shaft excavation)

- Places exposed to radiation or dioxin and other hazardous substances (structure demolition and removal work)

Adopting unmanned construction for work at such locations can be counted on to have the following effects.

- Improved safety

- Reduction of temporary work costs and safety measure costs

- Improved operating rate (shortening construction periods)

- More precise higher quality construction

For example, seabed dredging has been done from the surface using a conventional crab barge or pumping barge, but if dredging is done by an unmanned machine traveling on the seabed, the work can be done safely during heavy seas, sharply increasing the operating rate (work period) and execution precision (quality). This technology has already been used for more than ten years remotely controlled by a wired system.

\section{CONCLUSION}

The development and popularization of unmanned construction will have many effects: improving the safety of construction work at the same time as it shortens construction periods and guarantees high quality. This will, in turn, improve the image of the construction industry that tends to be negative in Japan and spur progress in IT and robotics.

In the future, we wish to accurately assess the present state and challenges facing unmanned execution technologies and work to popularize their use.

\section{REFERENCES}

1) Advanced Construction Technology Center (ACTEC) (editor): Handbook on the use of unmanned construction in emergencies (published in August 2001)

2) Ito H.: Understanding traveling cranes (published in December 1994) 